\title{
Poesia brasileira do século XVIII ao XXI
}

Flávia Amparo ${ }^{I}$

O Percursos de Antonio Carlos Secchin pela lírica brasileira, em especial como crítico e como autor de poesia, são conhecidos no meio literário e marcam uma carreira dedicada ao estudo de importantes escritores canônicos e não canônicos de nossa literatura e à retomada criativa que, em sua obra poética, propõe releituras desse importante legado.

Percursos da poesia brasileira constitui-se a partir de um acervo de artigos que congrega uma boa parte da produção crítica sobre poesia publicada por Secchin entre os anos 1996 e 2014, propondo, conforme o autor denomina, uma "leitura seletiva da trajetória de nossa lírica” (p.5). Curiosamente, no limiar do livro, no espaço que antecede o corpo de artigos que o compõem, o crítico e poeta seleciona textos lapidares que servirão de guia aos leitores nessa caminhada pelas veredas do poético: "Poesia e desordem" e "Memórias de um leitor de poesia". Essa antessala secchiniana, intitulada "Questões de princípios", apresenta-nos duas outras faces de sua trajetória, que constituem as bases de sua formação no universo das Letras - a do leitor e a do professor de poesia. O uso do plural para a expressão que nomeia essa primeira parte remete-nos aos princípios pelos quais a sua crítica se fundamenta e, da mesma forma, ao início do aprendizado poético, às suas “memórias prévias" do tempo de escola.

Esses textos de abertura, além de fazerem parte de obras homônimas do autor, representam os princípios norteadores que vão marcar a obra crítica secchiniana, apontando os parâmetros de análise da poesia e, ao mesmo tempo, conscientizando o leitor sobre a impossibilidade de fixar esses parâmetros. A aparente contradição na trajetória proposta pelo livro revela-nos que a poesia não será sumariamente domesticada pela clausura da crítica, muito menos vislumbrada no meio do caminho percorrido: teremos de buscá-la às margens do poema e expor-nos sempre ao iminente risco de perdê-la nas veredas sinuosas da linguagem:

Há muitos modos de aprisionar o transbordamento do mundo; não queiramos que a poesia seja mais um. Ela deve ser a palavra vigorosa diante de todo arbítrio classificatório, a voz que não se pode perceber senão nas margens. Por isso a poesia representa a fulguração da desordem, o "mau caminho" do bom senso, o sangramento inestancável do corpo da linguagem, não prometendo nada além de rituais para deus nenhum. (p.12)

O crítico sustenta o pressuposto de que o reino da poesia não se apresenta como um mundo ordenado e, por essa razão, é impossível guiar-se com precisão pelo fio de Ariadne da crítica. Ao crítico, cabe iluminar o poema, ainda que seja para constatar, na deriva dos sentidos, a pluralidade das vias pelas quais as palavras podem circular.

O trabalho exegético do escritor configura-se em cada artigo por um viés que costuma prestigiar as etapas de análise do literário e cumprir um ciclo hermenêutico pleno: contempla os conhecimentos informativos, analíticos e interpretativos necessários a uma melhor apreensão das obras estudadas. Significa 
dizer que há uma preocupação em esclarecer vertentes do poético relacionadas à compreensão dos sentidos e dos aspectos da erudição, ao estudo da estrutura e da técnica do poema e à análise crítica mais profunda, que estabelece os pontos de contato entre a obra e uma rede de conceitos intertextuais, associativos e simbólicos que a constituem.

A título de exemplo, o estudo que abre a segunda parte do livro, dedicado a Tomás Antônio Gonzaga, destaca a temática do eu lírico e da musa, em $\mathrm{Ma}$ rília de Dirceu, para revelar como essa proximidade entre ambos ecoa tanto nos sentidos do poema quanto na escolha da pessoa verbal usada na interlocução do eu lírico. De igual modo, observa que o número de estâncias dedicadas à amada corresponde numericamente às da Natureza, estabelecendo a simetria da construção do poema, em busca do equilíbrio clássico e da valorização dos principais atributos da musa a partir de seu espelhamento com o ambiente. Por fim, num arremate que quebra os clichês interpretativos do arcadismo brasileiro, o autor refuta uma visão unívoca da obra para admitir que há uma dupla via poética, em que simetria e assimetria se conjugam na construção dos sentidos:

O amor, portanto, não é apenas o bem-comportado sentimento a reboque de uma Natureza que, com regularidade, fecunda, produz e gera, mas também o vetor que desestabiliza o previsível ciclo da vida, introduz a assimetria, franqueia as portas da loucura. O estudo dos processos de recalque desse ímpeto entrópico, sublimado em tantos textos de Marília de Dirceu, talvez acrescente insuspeitadas doses de veneno ao anódino leite extraído do alegre e manso rebanho. (p.29)
O arremate do artigo sobre Gonzaga segue o percurso de análise que corresponde ao leitmotiv da crítica secchiniana, já previamente discutido na antessala do livro: o poético opera pelos princípios da ordem e da desordem, da tese e da antítese. O escritor consegue estabelecer, assim, a síntese da ideia primordial do poema ao concretizá-la na simbologia dos elementos leite/veneno, inserindo o pomo da discórdia nesse anódino Paraíso gonzaguiano.

A síntese constitui-se o ponto-chave dos desfechos de cada artigo do livro, momento de sublimação do poeta Antonio Carlos Secchin pelo viés do crítico - sua mania de beleza - no bom sentido da transfiguração da linguagem em busca do arremate perfeito. É admirável apreciar a fluência do autor e sua escolha pela palavra precisa que, unida ao seu caráter investigativo, traz ao leitor descobertas histórico-críticas enfeixadas pelas análises originais dos poemas.

Considerando essa questão, em "Gonçalves Dias: poesia e etnia", vemos uma combinação entre o estudo da obra e do contexto histórico e memorialístico do bardo maranhense, que inclui a leitura de alguns poemas e de duas cartas, além da análise de uma caricatura do poeta, de autoria de Angelo Agostini. Ao recompor a trajetória gonçalvina, Secchin traz elementos pouco conhecidos da biografia do autor, como o necrológio publicado por engano no jornal (dois anos antes de sua morte) e o caráter premonitório de algumas cartas, em que preconiza o mar como o túmulo digno de um trovador. $\mathrm{O}$ vaticínio efetivamente se confirma com o naufrágio do Ville de Boulogne, navio no qual retornava à terra natal com os manuscritos de "O timbiras", que foram perdidos no mar. 
Na construção do artigo sobre Gonçalves Dias, o crítico desdobra os sentidos da palavra "naufrágio", remetendo, na abertura do texto, ao juízo crítico de Agripino Grieco acerca do apagamento da obra ao longo dos anos e, também, ao contexto biográfico que marcou o desfecho da vida do poeta e que, igualmente, vai ilustrar o epílogo do artigo secchiniano. Assim sendo, o ato da escrita do texto simboliza a recomposição da memória do escritor, como tentativa de salvá-lo do duplo naufrágio, vaticinado pelo próprio poeta e pela crítica: "Espero que, contrariando o desencantado juízo de Agripino Grieco, aprendamos a mais querer o discurso poético de Gonçalves Dias, fazendo com que ele consiga soar e sobreviver a todos os naufrágios da memória brasileira" (p.70).

Os dois artigos escolhidos foram aqui detalhados para ilustrar alguns dos procedimentos críticos do livro, de modo a "dar a ver" as sutilezas que marcam a exegese secchiniana e que vão ecoar no contexto geral da obra sob variadas nuances. O leitor de poesia apropria-se do espaço da memória para redimensionar o olhar sobre cada obra - do arcadismo ao romantismo, do simbolismo ao parnasianismo, do modernismo à poesia contemporânea. Nos 42 artigos do livro dedicados ao estudo sistemático de poetas brasileiros, comparecem maciçamente os poetas românticos (oito artigos), seguidos pelos dois poetas preferidos do crítico, Drummond e João Cabral, aos quais vai dedicar duas suites, compostas de oito e cinco artigos, respectivamente, revelando a intensidade com que a melodia dos dois poetas acompanham, ininterruptamente, esse fundo musical do seu percurso crítico.

Embora concentrando-se particular- mente em Drummond, outros autores surgem na confraria dos poetas do livro - desde os conhecidos do cânone, como Álvares de Azevedo, Casimiro, Varela, Castro Alves, Cruz e Sousa, Cecília, Vinícius, Quintana, Jorge de Lima; até os mais esquecidos, como Mario Pederneiras e Vitoriano Palhares. Há ainda os menos óbvios, como Euclides da Cunha e Bernardo Guimarães, assim como os contemporâneos como Ferreira Gullar, Ivan Junqueira, Chico Buarque e Paulo Henriques Brito, além de outros escritores que marcam o panorama poético brasileiro dos séculos XX e XXI, que serão nomeados em dois artigos mais gerais do livro: "Poesia e gênero literário: alguns contemporâneos" e "Caminhos recentes da poesia brasileira". Este último é uma excelente recomposição dos principais movimentos da lírica do Brasil a partir da década de 1950, desde o surgimento do concretismo até os autores mais recentes.

Torna-se tarefa difícil capturar o essencial desses Percursos da poesia brasilei$r a$, obra plural, de grande fôlego e erudição, de modo que poderíamos chamá-la de "canto geral" da crítica de poesia no Brasil, uma vez que tão poeticamente se debruça sobre um legado de grande relevância literária. Podemos afirmar que Secchin apropria-se da matéria analisada e, tal como a "Consideração do poema", uma das primeiras composições de Drummond citadas no artigo "A rosa, o povo", parece-nos dizer que "Estes poetas são meus. De todo o orgulho,/ de toda precisão se incorporaram/ ao fatal meu lado esquerdo [...] / São todos meus irmãos, não são jornais $/[\ldots]$ é toda minha vida que joguei. // Estes poemas são meus. É minha terra/ e é ainda mais do que ela [...] (Andrade, 2008, p.21). 
O crítico define a literatura como “espaço mágico, que é o mais solitário e, ao mesmo tempo, o mais povoado de todos, espaço em que o indivíduo consegue transitar da solidão radical para a solidariedade mais irrestrita" (p.216). A definição ressignifica o leitmotiv da obra secchiniana, uma vez que o autor se coloca entre "a voz do texto e a escuta do leitor” (p.15), entre a singularidade de sua leitura e a pluralidade da poesia. Como nas palavras do poeta Estácio, na Divina comédia de Dante, direcionadas ao mestre Virgílio, cabe ao crítico ser o leitor primordial, a iluminar solidariamente os caminhos da poesia para os que acompanham, logo atrás, seus passos: "Facesti come quei che va di notte, / che porta il lume dietro e sé non giova, / ma dopo se fá le persone dotte [Fizeste como o caminhante noturno / que leva o seu lume às costas e a si mesmo não beneficia / mas faz sábio o que segue atrás de si]" (Alighieri, 1998, p.145, tradução nossa). O poeta há de sempre caminhar solitariamente no fértil deserto do poético, enquanto seus leitores seguem-lhe o percurso, saciando-se em suas fontes.

Referências

ALIGHIERI, D. A divina comédia. Purgatório. Trad. Ítalo Eugênio Mauro. São Paulo: Ed. 34, 1998.

ANDRADE, C. D. de. A rosa do povo. Rio de Janeiro: Record, 2008.

SECCHIN, A. C. Percursos da poesia brasileira. Do século XVIII ao XXI. Belo Horizonte: Autêntica Editora; Editora UFMG, 2018. 367p.

Flávia Amparo é professora associada de literatura brasileira da Universidade Federal Fluminense e do Colégio Pedro II.
@ - v.flavia@globo.com /

https://orcid.org/0000-0003-0614-6441

Recebido em 18.10.2018 e aceito em 20.11.2018.

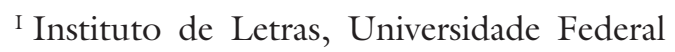
Fluminense, Niterói, Rio de Janeiro, Brasil. 